\title{
Gonadal alterations in male whitefish Coregonus fatioi: no evidence for genetic damage reducing viability in early life stages
}

\author{
Davnah Urbach ${ }^{1,2,7, *}$, Adrian Britschgi ${ }^{2,8}$, Alain Jacob $^{1,2,3}$, David Bittner ${ }^{4}$, \\ Daniel Bernet ${ }^{5}$, Thomas Wahli ${ }^{5}$, Nigel G. Yoccoz $^{6}$, Claus Wedekind ${ }^{1,2}$ \\ ${ }^{1}$ Department of Ecology and Evolution, Biophore, University of Lausanne, 1015 Lausanne, Switzerland \\ ${ }^{2}$ Division of Conservation Biology, University of Bern, Erlachstrasse 9, 3012 Bern, Switzerland \\ ${ }^{3}$ Natural History Museum, 3005 Bern, Switzerland \\ ${ }^{4}$ Computational and Molecular Populations Genetics (CMPG), Zoological Institute, University of Bern, Baltzerstrasse 6, \\ 3012 Bern, Switzerland \\ ${ }^{5}$ Centre for Fish and Wildlife Health, University of Bern, Laenggassstr. 122, PB 8466, 3001 Bern, Switzerland \\ ${ }^{6}$ Department of Biology, University of Tromsø, 9037 Tromsø, Norway \\ ${ }^{7}$ Present address: International Institute for Applied System Analysis, Schlossplatz 1, 2360 Laxenburg, Austria \\ ${ }^{8}$ Present address: Departement Klinische Forschung, University of Bern, MEM E829, Murtenstrasse 35, 3010 Bern, \\ Switzerland
}

\begin{abstract}
In recent years, numerous cases of morphological gonadal alterations in fish have been recorded throughout the world and across a wide range of species. In the whitefish Coregonus fatioi from the pre-alpine Lake Thun (Switzerland), the frequency of gonadal alterations is particularly high and the variety of alteration types large. Little is known about the proximal causes and the direct consequences of these morphological features on population persistence. In particular, the potential for the observed alterations to be the phenotypic expression of reduced genetic quality has not yet been addressed. In this study, we used offspring survival during embryogenesis as a proximate indicator of male genetic quality and tested whether the presence of gonadal alterations in males is an indicator of reduced quality. Embryos resulted from in vitro fertilizations of gametes from 126 males and females. We found no significant correlation between embryo survival and gonadal alteration in adults. Our findings suggest that in C. fatioi of Lake Thun, alterations in gonad morphology are not a phenotypic expression of variation in genetic quality.
\end{abstract}

KEY WORDS: Gonadal alterations · Genetic quality · Embryo survival $\cdot$ Whitefish $\cdot$ Lake Thun

\section{INTRODUCTION}

Numerous studies of fish populations document the widespread occurrence of gross gonadal morphology alterations, such as lobe divisions, asymmetries and atrophies. Examples are found in a large number of species, such as different whitefish species Coregonus spp., lake trout Salvelinus namaycush and roach Rutilus rutilus (Porter \& Corey 1974, Scott 1975, Ruby \& Cairns 1983, Hunter \& Macewicz 1985, Brown \&
Scott 1988, Wicklund \& Bylund 1994, Wicklund et al. 1996, Fitzsimons \& Cairns 2000, Simpson et al. 2000, Rodgers-Gray et al. 2001), and a wide range of locations throughout Europe (Sandström et al. 1988, Wicklund et al. 1996, Jobling et al. 1998), North America (Ruby \& Cairns 1983, Hunter \& Macewicz 1985, Fitzsimons \& Cairns 2000) and New Zealand (Kinnison et al. 2000).

In Switzerland, most of the larger lakes (Florin 1945, Steinmann 1951, Ruhlé 1983) and some rivers (Körner 
et al. 2005) are known for occasionally hosting intersex individuals, i.e. individuals characterized by the simultaneous presence of both male and female gonadal features (Nolan et al. 2001). However, the prevalence of some types of gonadal alterations is much higher in Lake Thun than in other Swiss waters. Lake Thun therefore appears as a unique case with respect to both the large variety of deviations and their high frequency (Bernet et al. 2004). Over a $3 \mathrm{yr}$ period of sampling, Bernet et al. (2004) recorded that $35 \%$ of whitefish (281 out of 808 fish) were affected, among them males and females of all age classes, from 1 to $6 \mathrm{yr}$, and individuals of different species (see Douglas et al. 1999 for a discussion of the taxonomy of Alpine whitefish). The deviations observed in these individuals included fusions to the trunk musculature, asymmetries, compartmentations, constrictions atrophy/aplasia and intersex (see Bernet et al. 2004 for a precise description of these alterations).

The reasons for the observed patterns are not clear yet, but several factors may individually or jointly affect gonadal morphology and development in fish. Hybridization, i.e. the mating of individuals from different species or subspecies, appears to be one of them (Chevassus 1983). Among the known environmental factors, temperature, parasites, and chemical substances are often cited as primary determinants (reviewed in Blazer 2002). Finally, hatchery management might add to the aforementioned exogenous factors. In particular, fertilization practices, such as single male or sequential fertilizations (Wedekind 2002, Wedekind \& Müller 2004, Wedekind et al. 2007), may decrease the overall genetic quality of individual fish, which in turn may affect gonadal morphology. As far as we know, there is no evidence for decreased rates of heterozygosity in our study population. However, the potential for variation in gonadal morphology to be the expression of reduced genetic quality has never been tested.

An individual is of reduced genetic quality when it possesses an allele or a genotype conferring low fitness relative to an individual with a different allele or genotype (Neff \& Pitcher 2005). Mutations triggered by environmental contaminants, inbreeding or genetic incompatibilities, for instance, might decrease genetic quality by providing individuals with suboptimal alleles or genotypes. Although lifetime reproductive success appears as the ultimate evidence for variation in genetic quality among individuals, other metrics, such as fluctuating asymmetry, may serve as useful indicators. Fluctuating asymmetries are small random deviations from perfect symmetry that arise due to the inability of individuals to buffer themselves against genetic and environmental stress during ontogeny (Van Valen 1962). The degree of fluctuating asymmetry is com- monly regarded as an indicator of developmental instability (van Dongen 2006) and of quality (Wedekind \& Müller 2004, Urbach et al. 2007). In the sample used for the present study, individuals with high fluctuating asymmetry and with at least some types of gonadal alterations were found to have faster sperm than other males (Urbach et al. 2007). Thus, and because increased sperm velocity may compensate for social, genetic and/or phenotypic disadvantages (Taborsky 1998, Rudolfsen et al. 2006, Urbach et al. 2007, Rudolfsen et al. 2008), gonadal malformations may also be regarded as an indicator of genetic quality and as another phenotypic expression of developmental instability.

Here we tested whether there is a link between the occurrence of gonadal alterations and genetic quality by monitoring an important aspect of offspring fitness, namely embryo viability from fertilization until hatching. If the aberrant development of gonadal tissues is a phenotypic expression of reduced genetic quality, parental individuals displaying gonadal alterations would be expected to sire embryos of reduced viability. Because correlations between embryo survival and other indicators of male genetic quality could occur and mask the link we were interested in, we also investigated the correlations between male age and genetic quality.

\section{MATERIALS AND METHODS}

Fish sampling, fertilizations and egg rearing. In mid-December 2004, we caught 66 sexually mature male and 60 sexually mature female Albock Coregonus fatioi, Kottelat by bottom gillnets on 1 spawning ground in Lake Thun, at about $30 \mathrm{~m}$ depth. We killed each fish by a blow to its head, dried the area around the genital pore to avoid sample contamination and collected the gametes in individual Petri dishes. We then subdivided the eggs into batches and fertilized them block-wise, following a North Carolina II design (NCII) for each block (Lynch \& Walsh 1998). That is, within each block, on average 4 to 6 males fertilized individually the eggs of a similar number of females, according to a fully factorial breeding design. Thus, within each block, all possible parental combinations were represented. Eventually, any given male fertilized eggs of a minimum of 2 and a maximum of 6 females and each female was crossed with 4 to 6 different males. We used $10 \mu \mathrm{l}$ of milt for each batch of eggs fertilized. We activated the sperm and induced fertilization by adding a few $\mathrm{ml}$ of lake water to the eggs, and shortly moved each dish in circles to ensure homogenous milt repartition. We filled up the dishes with lake water about 2 min later and left them undisturbed for at least $30 \mathrm{~min}$ to allow for egg hardening. 
After this period, we emptied each dish into a tea strainer and rinsed the freshly fertilized eggs with approximately $2 \mathrm{l}$ of sand-filtered lake water before pouring them into a new Petri dish filled with sand-filtered lake water. We then brought the resulting 275 parental combinations to a climate chamber. The following day, we distributed the embryos from each combination about evenly to 3 new Petri dishes filled with temperated and oxygenated tap water. Embryos were reared at approximately $7^{\circ} \mathrm{C}$.

During the first $7 \mathrm{wk}$ after fertilization, we monitored 'early embryo mortality' by counting and removing dead eggs at intervals of 1 or $2 \mathrm{wk}$. Water was exchanged every second week by emptying the eggs over a stiff nylon net, pouring them back into the dish and refilling the dish with temperated and oxygenated tap water. We observed the first hatchlings after $7 \mathrm{wk}$. From then on, we checked the dishes daily and monitored the number of newly hatched larvae and of dead embryos. This mortality was recorded as 'late embryo mortality.' Water was not exchanged during this latter period.

Gonad description of the parental fish. After stripping, parental fish were dissected and their gonads morphologically assessed. Based on Bernet et al. (2004), the morphological features were categorized into constrictions, asymmetries, aplasia, compartmentations, fusions and intersex. According to D. Bittner (unpubl. data), asymmetries and constrictions appear to represent essentially natural variation in gonad morphology among whitefish. Consequently only aplasia, compartmentations, fusions and intersex should be regarded as true gonad deformations. However, although asymmetries and constrictions may be regarded as morphological variation rather than deformations per se, they nevertheless represent deviations from 'normal' gonad morphology (i.e. non-deformed and not obviously asymmetric) and were considered as such in subsequent analyzes. That is, the gonads were categorized into 3 categories: deformed (fusions, aplasia, compartmentations, intersex), morphologically deviated (constrictions and asymmetries) and normal.

Age determination of the parental fish. We collected 10 scales from between the adipose fin and the branch line of each individual and prepared them for scalimetry. We used the annulus-criteria of Berg \& Grimaldi (1967) on the scale showing the clearest annuli to determine the age of the fish.

Statistical analyses. Statistical analyses were performed using the software R v. 2.1.1 (R Development Core Team 2006). First, we tested for variation among age classes in the prevalence of gonadal alterations of either type. For this analysis, we used a generalized linear model and assumed a binomial distribution for the occurrence of anomalies. Second, we investigated the links between embryo mortality and age, and between embryo mortality and gonadal anomalies. Because of an unexpected correlation between initial egg number per Petri dish and male size, the link between embryo mortality and male size versus growth rate could not be established safely. The mortality data we collected both before and after the first hatching event ranged from 0 to $100 \%$ and were not normally distributed. Consequently, ordinary leastsquares multiple regressions were not applicable and a proportional hazard model was chosen. The hazard function assesses the instantaneous risk of death at any time, conditional on survival to that time. As we monitored mortality weekly before the embryos started to hatch and daily afterwards, we chose the discrete time analog of the proportional hazards model (Cox 1972). Moreover, we performed 2 separate analyses for early and late embryo mortality. The discrete time analog of the proportional hazards model (Cox 1972) assumes a binomial distribution for the number of eggs dying and a complementary log-log (clog-log) link:

$$
\{\log [-\log (1-p)]\}
$$

where $p=$ proportion of dead eggs. Such links are commonly used for variables that lie in the unit interval, as is the case here. Because mortalities were measured on 3 replicates within each female $\times$ male combination and each male was combined with several different females, we used a mixed model approach and defined males, females and replicates within sib-ship as random factors. The occurrence of alterations or individual age, and the cumulative number of days from fertilization until each control date were considered as fixed variables. Reliable convergence of the generalized linear mixed models could not be achieved when assuming a complementary log-log link and a binomial distribution. Therefore, we used a linear mixed effect model, which we implemented in the lmer function (Bates 2005). This implied using empirical clog-logs instead of the common clog-logs. Empirical clog-logs were calculated based on Cox \& Snell (1989). However, in order to circumvent problems of non-defined boundaries resulting from observed $\mathrm{p}$ equal to 0 or 1 , the formula was adapted as follows:

$$
\log \left\{\log \left[\left(N_{\text {total }}+1\right) /\left(N_{\text {alive }}+0.5\right)\right]\right\}
$$

where $N_{\text {total }}+1=\left(N_{\text {alive }}+0.5\right)+\left(N_{\text {dead }}+0.5\right)(\mathrm{Cox} \&$ Snell 1989). Because fully factorial crossing designs were only applied within blocks and because some females appeared in several different blocks, females were either crossed with or nested within males and results were compared. Additionally, we also used a proportional odds model (Collett 1991) and arcsinetransformed daily mortalities (arcsin $\sqrt{m o r t}$ ) as response variables. The proportional odds model (Collett 1991) assumes a logit link: 


$$
\log [\mathrm{p} /(1-p)]
$$

We calculate the empirical logits necessary for the use of a linear mixed effect model according to Cox and Snell (1989):

$$
\log \left[\left(N_{\text {dead }}+0.5\right) /\left(N_{\text {alive }}+0.5\right)\right]
$$

Daily mortalities were obtained according to the following formula:

$$
1-\left[(1-p)^{1 / d}\right]
$$

All models provided consistent results. The results we show correspond to a proportional hazards model with crossed males and females. Because of the low number of females in which gonadal alterations were observed, estimated effects of alterations on embryo survival ( $\beta$ ) are given with their $95 \% \mathrm{CI}$ in addition to the test statistics. CIs were calculated on the nested model.

\section{RESULTS}

Among the 66 males and 60 females, 8 males (12\%) and 1 female $(2 \%)$ had compartmentations and/or fusions (i.e. deformed gonads); 36 males (55\%) and 3 females $(5 \%)$ had constrictions and/or asymmetries (i.e. morphologically deviated gonads); and 26 males $(39 \%)$ and 56 females (93\%) showed no unusual morphological features (i.e. normal gonads). No intersex individuals were recorded and no case of aplasia was observed. Six males were of age $2+, 38$ of age $3+$ and 21 of age $4+$. Because only 1 individual was observed in age class $5+$, this class was discarded.

There was no significant link between the occurrence of deformations or deviations and male age (compartmentations and fusions: $\mathrm{df}=65,0.00<z<$ $0.006, \mathrm{p}>0.9$; constrictions and asymmetries: $\mathrm{df}=65$, $-0.082<z<-0.011, \mathrm{p}>0.4)$.

Both early and late embryo mortality changed over time, i.e. mortality rates varied from 1 control date to the next (from week to week or every second week during early development: $F_{5,203}=765.1, \mathrm{p}<0.01$, and from day to day during late development: $F_{42,531}=$ $509.04, \mathrm{p}<0.01$ ). Time was consequently accounted for in these analyses by keeping the time factor among the predictors. We found no significant link between the occurrence of abnormal gonadal features and embryo survival until hatching. This was true for both early and late embryo mortality and regardless of the morphological category. That is, in males the occurrence of compartmentations and/or fusions was not significantly linked to offspring mortality, either during early embryogenesis $\left(F_{1,63}=2.75, \mathrm{p}=0.102\right)$ or during late embryogenesis $\left(F_{1,63}=0.51, \mathrm{p}=0.48\right)$. No significant relationship was observed either between the occur-

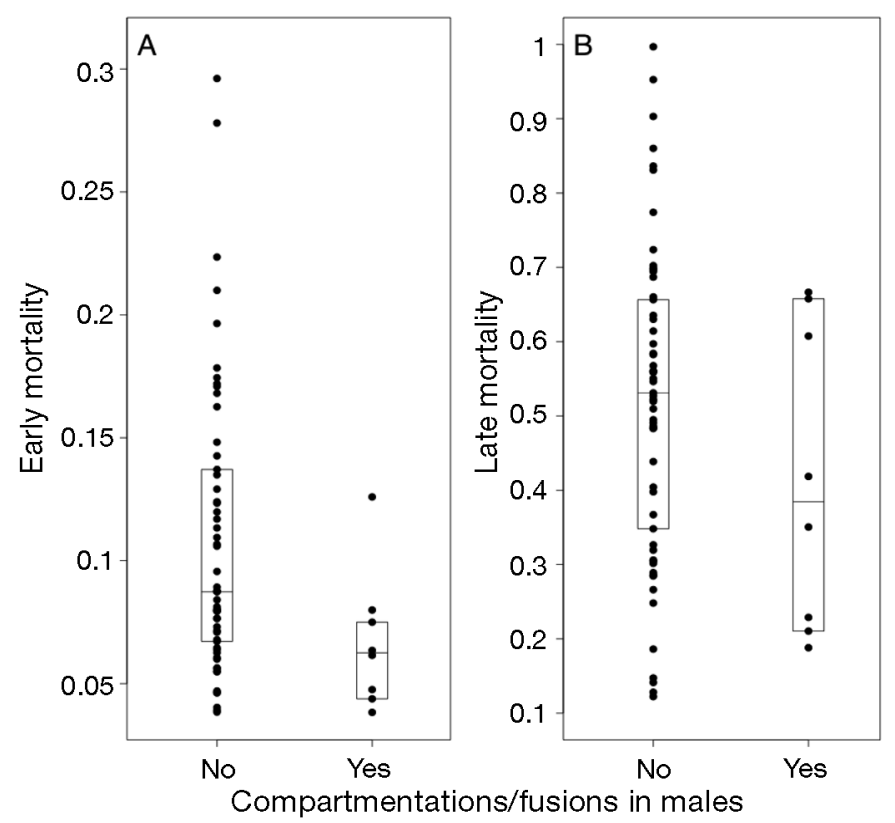

Fig. 1. Coregonus fatioi. Mortality among embryos sired by males with or without compartmentations and/or fusions of their gonads: (A) proportion of eggs that died during the first 7 wk of embryogenesis (early embryo mortality); (B) proportion of eggs that died during the remaining 4 wk preceding hatching (late mortality). Each dot represents the mean proportion of dead eggs per male. Boxes show medians and upper and lower quartiles

rence of constrictions and/or asymmetries and early $\left(F_{1,63}=1.93, \mathrm{p}=0.17\right)$ and late embryo mortality $\left(F_{1,63}=\right.$ $0.79, p=0.38)$, respectively. Figs. $1 \& 2$ show mean early and late embryo mortality for each siring male characterized or not by compartmentations and/or fusions (Fig. 1) and by constrictions and/or asymmetries (Fig. 2). Finally, no significant link was detected between embryo mortality and male age. That is, early and late mortality were not found to vary among male age classes (early mortality: $F_{2,62}=0.102, \mathrm{p}=0.90$; late mortality: $F_{2,531}=0.51, \mathrm{p}=0.6$ ). Mean early and late embryo mortality for each male in each age class are shown in Fig. 3.

Among females, no significant relationship was detected between early $\left(F_{1,58}=3.0, p=0.09, \beta=0.45\right.$, $95 \% \mathrm{CI}=-0.08,0.98)$ and late $\left(F_{1,58}=0.36, \mathrm{p}=0.55, \beta=\right.$ $0.17,95 \% \mathrm{CI}=-0.39,0.72$ ) embryo survival and the occurrence of constrictions and/or asymmetries.

\section{DISCUSSION}

We tested whether the occurrence of abnormal gonadal features in adult whitefish is linked to increased mortality rates during early and late 


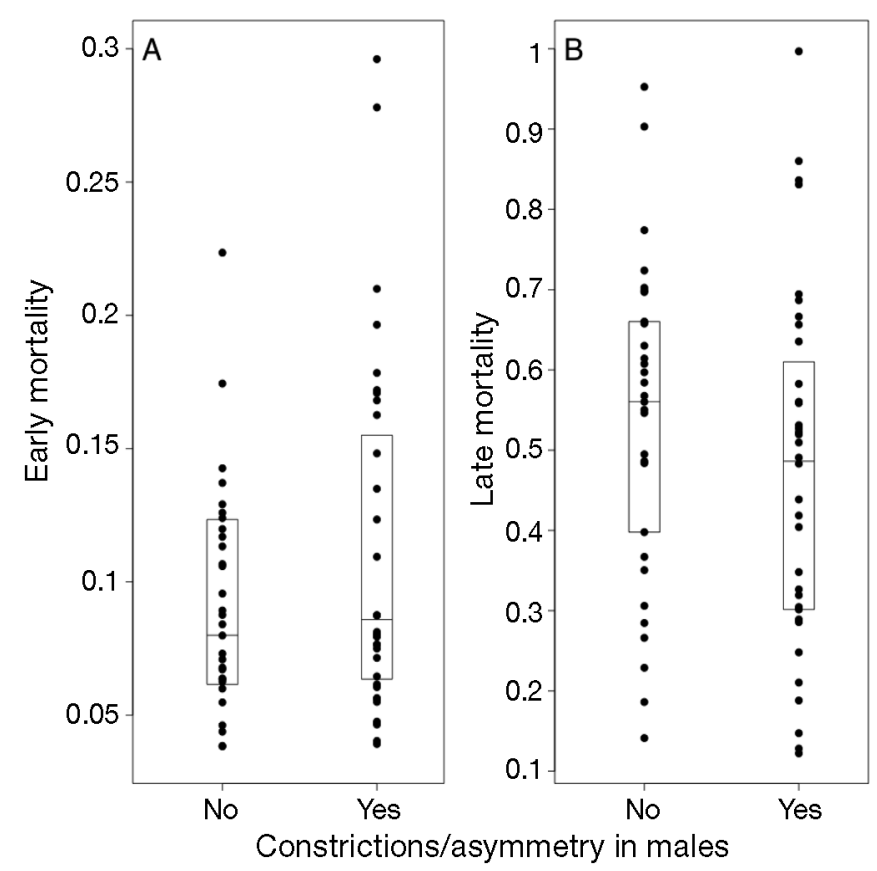

Fig. 2. Coregonus fatioi. Mortality among embryos sired by males with or without constrictions and/or asymmetries of their gonads: (A) proportion of eggs that died during the first 7 wk of embryogenesis (early embryo mortality); (B) proportion of eggs that died during the remaining 4 wk preceding hatching (late mortality). Each dot represents the mean proportion of dead eggs per male. Boxes show medians and upper and lower quartiles cant link between the occurrence of particular anomalies in females and embryo survival should be taken with caution. Although particularly low, the prevalence of alterations amongst females is in lines with recent estimations across sexes in the Albock form (D. Bittner unpubl. data).

The absence of significant alteration in early embryo survival across males suggests that in this population of whitefish, morphological variations of the male reproductive apparatus do not significantly impair gametogenesis. This is confirmed by histological assessments of gamete development (D. Bernet pers. comm.). Moreover, given the low rates of early mortality that we recorded, non-fertilized eggs seemed to be rare, which suggests that gonadal alterations do not cause a significant reduction in gamete quality.

The whitefish species sampled for this study is the only one in Lake Thun supported by stocking (Bernet et al. 2004). Based on our results, the genetic alterations that might be brought about by particular hatchery practices do not seem to represent a major threat to male fertility. Moreover, since other whitefish forms in the same lake suffer from a significantly higher prevalence of altered gonads (Bernet et al. 2004, D. Bittner unpubl. data), it seems unlikely that hatchery practices cause the abnormal development of the gonadal tissues we observed.

In teleosts, maternal environmental effects are crucial determinants of offspring fitness (Brooks et al. embryogenesis in their progeny. We found no evidence for such a relationship; individuals with abnormal gonadal characteristics did not sire offspring with significantly reduced fitness at that developmental stage. Moreover, we found no significant link between embryo survival and male age. These results therefore suggest that in our study population of Lake Thun, males with gonadal deformations and/or deviations may not be of lower genetic quality than other males. However, we did not collect any information about embryo morphology, either before or after emergence, and we made no attempt to detect potential morphological anomalies during embryonic development. Embryo viability is only one of several possible measures of individual fitness and a long-term monitoring of offspring viability is still lacking. Additionally, further indicators of genetic quality, such as heterozygote deficit or levels of admixture between different forms of whitefish, may be useful. Moreover, because of the low number of affected females and the large CIs around the mean embryo survival, the absence of a signifi-

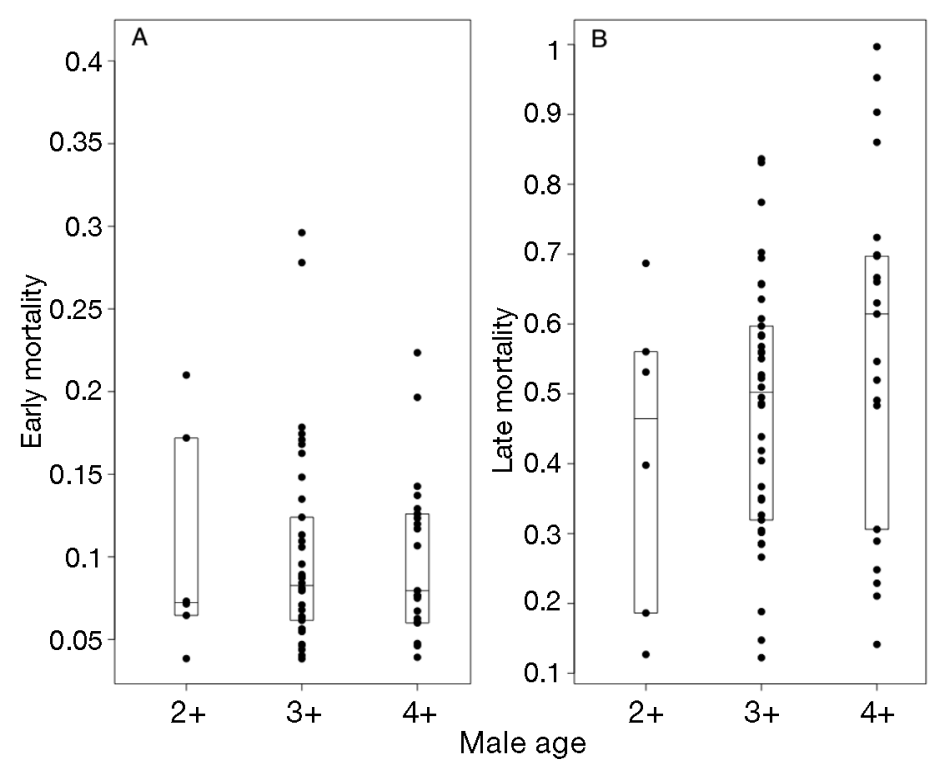

Fig. 3. Coregonus fatioi. Mortality among embryos sired by males of different age classes: (A) proportion of eggs that died during the first 7 wk of embryogenesis (early embryo mortality); (B) proportion of eggs that died during the remaining $4 \mathrm{wk}$ preceding hatching (late mortality). Each dot represents the mean proportion of dead eggs per male. Boxes show the medians and the upper and lower quartiles 
1997, Marteinsdottir \& Steinarsson 1998, Einum \& Fleming 1999, Wedekind et al. 2001, Rudolfsen et al. 2005, Johnston et al. 2007). Consequently, given the important role of the female reproductive tissues for the outcome of egg development, the putative relationship between morphological gonadal aberrations in females and egg production, egg quality and reproductive success requires further investigations.

This study addressed the possibility that abnormal gonadal features are a phenotypic expression of reduced genetic quality by evaluating whether variation in fitness exists among whitefish males displaying or not displaying deformations or deviations. Offspring survival during embryogenesis was not significantly dependent on the occurrence of particular gonadal features. This suggests that gonadal deformations and deviations do not reflect reduced genetic quality. However, we only looked at embryo survival, and detrimental fitness consequences could still be possible at later developmental stages.

Acknowledgements. We are grateful to M. M. Bia, U. Lehmann, B. von Siebenthal and R. Gingold for technical assistance, K. Klopfenstein for catching the fish and C. Küng, R. Arlettaz and R. Müller for general support. The project was funded by the Swiss National Science Foundation.

\section{LITERATURE CITED}

Bates D (2005) Fitting linear mixed models in R. R news. 5(1):27-30

Berg A, Grimaldi E (1967) A critical interpretation of the scale structures used for determination of annuli in fish growth studies. Mem Ist Ital Idrobiol 21:225-239

Bernet D, Wahli T, Kueng C, Segner H (2004) Frequent and unexplained gonadal abnormalities in whitefish (central alpine Coregonus sp.) from an alpine oligotrophic lake in Switzerland. Dis Aquat Org 61:137-148

Blazer VS (2002) Histopathological assessment of gonadal tissue in wild fishes. Fish Physiol Biochem 26:85-101

Brooks S, Tyler CR, Sumpter JP (1997) Egg quality in fish: what makes a good egg? Rev Fish Biol Fish 7:387-416

Brown EAR, Scott DBC (1988) A second hermaphrodite specimen of Coregonus lavaretus (L) (Salmonidae, Coregoninae) from Loch Lomond, Scotland. J Fish Biol 33:957-958

Chevassus B (1983) Hybridization in fish. Aquaculture 33: 245-262

Collett D (1991) Modelling binary data. Chapman \& Hall, London

Cox DR (1972) Regression models and life-tables. J R Stat Soc (Ser A) 34:187-220

Cox DR, Snell EJ (1989) Analysis of binary data. Chapman \& Hall, London

Douglas MR, Brunner PC, Bernatchez L (1999) Do assemblages of Coregonus (Teleostei: Salmoniformes) in the Central Alpine region of Europe represent species flocks? Mol Ecol 8:589-603

Einum S, Fleming IA (1999) Maternal effects of egg size in brown trout (Salmo trutta): norms of reaction to environmental quality. Proc R Soc Lond B Biol 266:2095-2100

Fitzsimons JD, Cairns VW (2000) Prevalence of a testicular anomaly in lake trout (Salvelinus namaycush) of the Great Lakes basin. J Gt Lakes Res 26:74-81

Florin J (1945) Bemerkungen zum Fund eines zwittrigen Grossfelchens (Féra) aus dem Genfersee. Schweiz Fisch Zgt 5:134-138

Hunter JR, Macewicz BJ (1985) Rates of atresia in the ovary of captive and wild northern anchovy, Engraulis mordax. Fish Bull (Wash DC) 83:119-136

Jobling S, Nolan M, Tyler CR, Brighty G, Sumpter JP (1998) Widespread sexual disruption in wild fish. Environ Sci Technol 32:2498-2506

Johnston TA, Wiegand MD, Leggett WC, Pronyk RJ and others (2007) Hatching success of walleye embryos in relation to maternal and ova characteristics. Ecol Freshw Fish 16: 295-306

Kinnison MT, Unwin MJ, Jara F (2000) Macroscopic intersexuality in salmonid fishes. NZ J Mar Freshw Res 34: 125-134

Körner O, Vermeirssen ELM, Burkhardt-Holm P (2005) Intersex in feral brown trout from Swiss midland rivers. J Fish Biol 67:1734-1740

Lynch M, Walsh B (1998) Genetics and analysis of quantitative traits. Sinauer Associates, Sunderland, MA

Marteinsdottir G, Steinarsson A (1998) Maternal influence on the size and viability of Iceland cod (Gadus morhua) eggs and larvae. J Fish Biol 52:1241-1258

Neff BD, Pitcher TE (2005) Genetic quality and sexual selection: an integrated framework for good genes and compatible genes. Mol Ecol 14:19-38

> Nolan M, Jobling S, Brighty G, Sumpter JP, Tyler CR (2001) A histological description of intersexuality in the roach. J Fish Biol 58:160-176

Porter TR, Corey S (1974) Hermaphroditic lake whitefish, Coregonus clupeaformis, from lake Huron. J Fish Res Board Can 31:1944-1945

R Development Core Team (2006) R: A language and environment for statistical computing. R Foundation for Statistical Computing, Vienna

> Rodgers-Gray TP, Jobling S, Kelly C, Morris S and others (2001) Exposure of juvenile roach (Rutilus rutilus) to treated sewage effluent induces dose-dependent and persistent disruption in gonadal duct development. Environ Sci Technol 35:462-470

Ruby SM, Cairns V (1983) Implications of testicular constrictions on spermatogenesis in Lake Ontario lake trout, Salvelinus namaycush. J Fish Biol 23:385-395

Rudolfsen G, Figenschou L, Folstad I, Nordeide JT, Soreng E (2005) Potential fitness benefits from mate selection in the Atlantic cod (Gadus morhua). J Evol Biol 18:172-179

Rudolfsen G, Figenschou L, Folstad I, Tveiten H, Figenschou M (2006) Rapid adjustments of sperm characteristics in relation to social status. Proc R Soc Lond Ser B Biol 273: 325-332

Rudolfsen G, Muller R, Urbach D, Wedekind C (2008) Predicting the mating system from phenotypic correlations between life-history and sperm quality traits in the Alpine whitefish Coregonus zugensis. Behav Ecol Sociobiol 62: $561-567$

Ruhlé C (1983) Bemerkungen zum Fund eines zwittrigen Kleinfelchen (Albeli, Coregonus lavaretus L.) aus dem Walensee. Fisch Fisch 1:2

Sandström O, Neuman E, Karas P (1988) Effects of a bleached pulp mill effluent on growth and gonad function in Baltic coastal fish. Water Sci Technol 20:107-118

Scott DBC (1975) Hermaphrodite specimen of Coregonus lavaretus (L) (Salmoniformes, Salmonidae) from Loch Lomond, Scotland. J Fish Biol 7:709 
Simpson MG, Parry M, Kleinkauf A, Swarbreck D, Walker P, Leah RT (2000) Pathology of the liver, kidney and gonad of flounder (Platichthys flesus) from a UK estuary impacted by endocrine disrupting chemicals. Mar Environ Res 50: 283-287

Steinmann P (1951) Ein vollreifer Felchenzwitter. Schweiz Fish Ztg 57:15-16

Taborsky M (1998) Sperm competition in fish: 'bourgeois' males and parasitic spawning. Trends Ecol Evol 13: 222-227

Urbach D, Bittner D, Lenz TL, Bernet D, Wahli T, Wedekind C (2007) Sperm velocity in an Alpine whitefish: effects of age, size, condition, fluctuating asymmetry and gonad abnormalities. J Fish Biol 47(3):672-683

van Dongen S (2006) Fluctuating asymmetry and developmental instability in evolutionary biology: past, present and future. J Evol Biol 19:1727-1743

- Van Valen L (1962) A study of fluctuating asymmetry. Evolution 16:125-142

- Wedekind C (2002) Sexual selection and life-history deci-

Editorial responsibility: Thomas Braunbeck,

Heidelberg, Germany sions: implications for supportive breeding and the management of captive populations. Conserv Biol 16: $1204-1211$

Wedekind C, Müller R (2004) Parental characteristics versus egg survival: towards an improved genetic management in the supportive breeding of lake whitefish. Ann Zool Fenn 41:105-115

Wedekind C, Müller R, Spicher H (2001) Potential genetic benefits of mate selection in whitefish. J Evol Biol 14: 980-986

Wedekind C, Rudolfsen G, Jacob A, Urbach D, Müller R (2007) The genetic consequences of hatchery-induced sperm competition in a salmonid. Biol Conserv 137:180-188

Wicklund T, Bylund G (1994) Reproductive disorder in roach (Rutilus rutilus) in the Northern Baltic Sea. Bull Eur Assoc Fish Pathol 14:159-162

Wicklund T, Lounasheimo L, Lom J, Bylund G (1996) Gonadal impairment in roach Rutilus rutilus from Finnish coastal areas of the northern Baltic Sea. Dis Aquat Org 26: $163-171$

Submitted: August 21, 2007; Accepted: May 7, 2008

Proofs received from author(s): August 8, 2008 